\title{
Methodology and results of studying soil moisture after the interaction with the operating devices
}

\author{
Galina Parkhomenko,", Igor Bozhko ${ }^{1}$, Sergey Kambulov ${ }^{1}$, Andrey Boyko ${ }^{2}$, Oleg \\ Polushkin $^{2}$, Viacheslav Lebedenko ${ }^{2}$, Alexey Beskopilniy ${ }^{2}$, and Anastasiya Olshevskaya ${ }^{2}$ \\ ${ }^{1}$ State Scientific Establishment "Agricultural Research Center "Donskoy", 14, Lenin st., 347740, \\ Zernograd, Russia \\ ${ }^{2}$ Don State Technical University, 1, Gagarin sq., 344003, Rostov on Don, Russia
}

\begin{abstract}
Operating devices for soil cultivation in arid conditions should not carry the lower layers to the surface of the field, since this leads to the loss of moisture due to its evaporation. Purpose of work is to determine the moisture content in the soil after using new operating devices. There been developed technique of determining the moisture content in the soil after exposure to operating devices by studying the movement of soil layers in the vertical direction and comparing their moisture. The movement of soil in the vertical direction is quantified by a comparative study of the moisture content in the upper and lower layers of the treated formation before and after exposure to operating devices. Using appropriate equipment, there were determined the moisture content in the most susceptible to evaporation surface layer of $0-5 \mathrm{~cm}$ and then the average value of the layer-by-layer measurement up to a depth of $25 \div 35 \mathrm{~cm}$, depending on the selected operating modes of the operating device.
\end{abstract}

\section{Introduction}

In conditions of dry farming, the available moisture reserves inside the soil are of particular importance for the growth and development of agricultural crops [1, 2]. Therefore, the operating devices for soil cultivation in these conditions should not take out the lower layers on the field surface, since this leads to the loss of moisture due to its evaporation.

The authors of [3] noted that the ratio of actual evaporation to potential one is directly controlled by the moisture content in the soil inside the treated formation. In arid conditions, the yield of grain crops increases slightly with a moisture reserve inside the soil layer [4]. According to studies [5], the yield of grain crops has a positive correlation coefficient with the development of their shallow and deep root systems in drought conditions. Therefore, the soil layer must have a loose structure for the development of the root system of crops. This is confirmed by the authors of [6], who developed a biophysical model that establishes the relationship between the actual evapotranspiration and the

*Corresponding author: parkhomenko.galya@yandex.ru 
moisture content in the soil of the root zone with the predicted yield in arid conditions, that is suitable for use in analyzing the causes of spatial and temporal variability in grain production and the consequences of future scenarios, such like climate change [7]. The deformation of the formation in interaction with the operating devices is considered basing on the analysis of the viscoelastic and plastic properties of the soil $[8,9]$. Purpose of work is to determine the moisture content in the soil after using new operating devices.

\section{Materials and methods}

Measurement of soil moisture must be carried out directly in the field, since in the laboratory the natural structure of the sample is destroyed. The space between the microand macro-aggregates of the soil inside the formation is represented by air pores, hollows and cracks with other thermophysical characteristics; therefore, any change in the natural structure of the processed medium significantly affects the measurement results.

The measurement of the sought-for values in the field presents certain difficulties. In addition to complexity and cumbersomeness, as well as large investment of time (for example, with the gravimetric method for determining moisture), gross errors may arise due to the action of local random factors. There has been developed technique for studying the moisture content in the soil immediately after exposure to working organs. The methodology is based on a method for comparing the moisture content of various soil layers in the vertical direction. Using this method, the movement of soil layers after processing and the unwanted moisture removal to the field surface are also determined. The movement of soil in the vertical direction can be quantified by comparative study of the moisture content in the upper and lower layers of the treated formation before and immediately after exposure to operating devices.

In this case, using the appropriate equipment (Figure 1), there are determined the moisture content in the most susceptible to evaporation surface layer of $0-5 \mathrm{~cm}$ and then the average value of the layer-by-layer measurement up to a depth of $25 \div 35 \mathrm{~cm}$, depending on the selected operating modes of the operating device. To control the measurement depth, the probe has a scale with a division of $5 \mathrm{~cm}$ (Figure 1). Measurements are taken immediately after the passage of the operating devices. Soil moisture, according to the recommendations of normative documentation, can be determined by any method, the measurement error of which does not exceed $\pm 1 \%$. The design of the electronic device for measuring humidity (Figure 1) allows getting data to a depth of $35 \mathrm{~cm}$ or more. 
Fig. 1. Soil moisture meter.

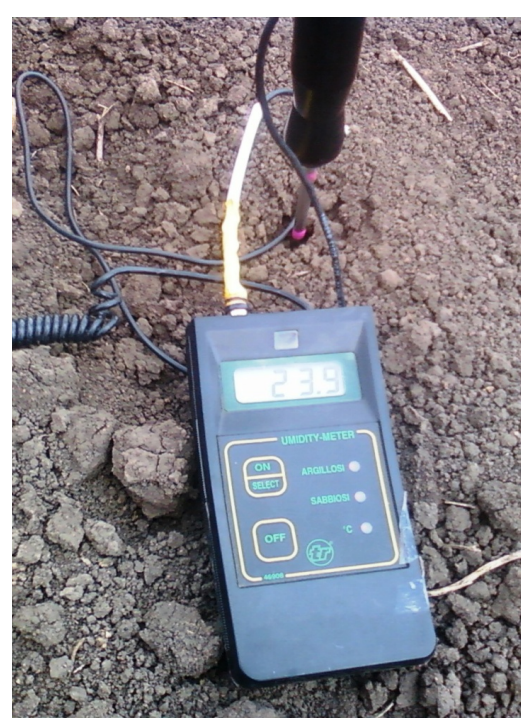

\section{Research results}

Change in moisture content after exposure of working bodies to the soil layer $\xi$ determined depending on the humidity of the corresponding layer to $W_{\text {before }}$ and after $W_{\text {after }}$ passage according to the:

The change in moisture content after exposure to operating devices of the soil layer $\xi$ is determined depending on the moisture content of the corresponding layer before $W_{\text {before }}$ and after $W_{\text {after }}$ passage according to the formula:

$$
\xi=\frac{W_{\text {after }}-W_{\text {before }}}{W_{\text {before }}} \cdot 100 \%
$$

The studies were conducted on three different backgrounds:

- on stubble of winter wheat with preliminary disking in one trace (I);

- on stubble of winter barley with preliminary disking in one trace (II);

- on bare fallow (III).

Humidity before the passage of the operating devices in the cultivated soil layer was determined to a depth of $0-5 \mathrm{~cm}$ and up to $25-35 \mathrm{~cm}$ on average, according to the research methodology, and amounted to:

- background I: $0-5 \mathrm{~cm}-24.8 \% ; 5-25 \div 35 \mathrm{~cm}-27.8 \%$;

- background II: $0-5 \mathrm{~cm}-22.4 \% ; 5-25 \div 35 \mathrm{~cm}-25.3 \%$;

- background III: $0-5 \mathrm{~cm}-18.7 \% ; 5-25 \div 35 \mathrm{~cm}-20.1 \%$.

Humidity is normal (up to $30 \%$ ).

The new operating devices are designed for layer-by-layer subsurface tillage in arid conditions, have a transformable structure containing a stand with a deep ripper in the form of a chisel, and are equipped with subsurface cultivator or curvilinear ripper or polymeric materials depending on the physicomechanical properties of the processed medium and the weediness of the field. The results of the study are presented in Table 1. 
Table 1. The results of the studying moisture content in the soil after the passage of new operating devices operating on different backgrounds.

\begin{tabular}{|c|c|c|c|}
\hline \multirow[b]{2}{*}{$\begin{array}{l}\text { The variant of the } \\
\text { new operating device }\end{array}$} & \multirow[b]{2}{*}{ Background } & \multicolumn{2}{|c|}{ Indicator value } \\
\hline & & $\begin{array}{c}\text { Humidity in the } \\
\text { layer of } 0-5 \mathrm{~cm} \\
\text { after tillage } W_{\text {after }}, \\
\%\end{array}$ & $\begin{array}{c}\text { Change in moisture } \\
\text { content in the layer } \\
\text { of } 0-5 \mathrm{~cm} \\
\xi, \%\end{array}$ \\
\hline \multirow{3}{*}{$\begin{array}{l}\text { with } \\
\text { subsurface cultivator }\end{array}$} & background I & 22.5 & reduced by 9.3 \\
\hline & background II & 21.6 & reduced by 3.6 \\
\hline & background III & 18.1 & reduced by 3.2 \\
\hline \multirow{3}{*}{ with curvilinear ripper } & background I & 23.4 & reduced by 5.6 \\
\hline & background II & 22.0 & reduced by 1.8 \\
\hline & background III & 18.3 & reduced by 4.6 \\
\hline \multirow{3}{*}{$\begin{array}{l}\text { with polymeric } \\
\text { materials }\end{array}$} & background I & 25.0 & increased by 0.8 \\
\hline & background II & 22.1 & reduced by 1.3 \\
\hline & background III & 17.9 & reduced by 4.3 \\
\hline
\end{tabular}

The analysis of the data in Table 1 indicates that when the operating devices function according to the stubble backgrounds of winter wheat and winter barley after one-track disking and bare fallow , the removal of the lower soil layers to the surface is not observed, since in almost all variants and modes the humidity does not increase after processing.

Slight increase (by $0.8 \%$ ) in the moisture content in the surface layer within the experimental error $(1.01 \%)$ was observed during the functioning of the operating device with polymeric materials against the stubble background of winter wheat. The most significant decrease in moisture content in the surface soil layer against the stubble background of winter wheat for other operating devices is explained by the nonequilibrium state of weather conditions (strong wind after precipitation on the eve).

There was compared moisture content in the soil after the passage of new operating devices and moldboard plough as performing the main tillage. General view of the processed field with a moldboard plow (right) and new operating devices (left) is presented in Figure 2.

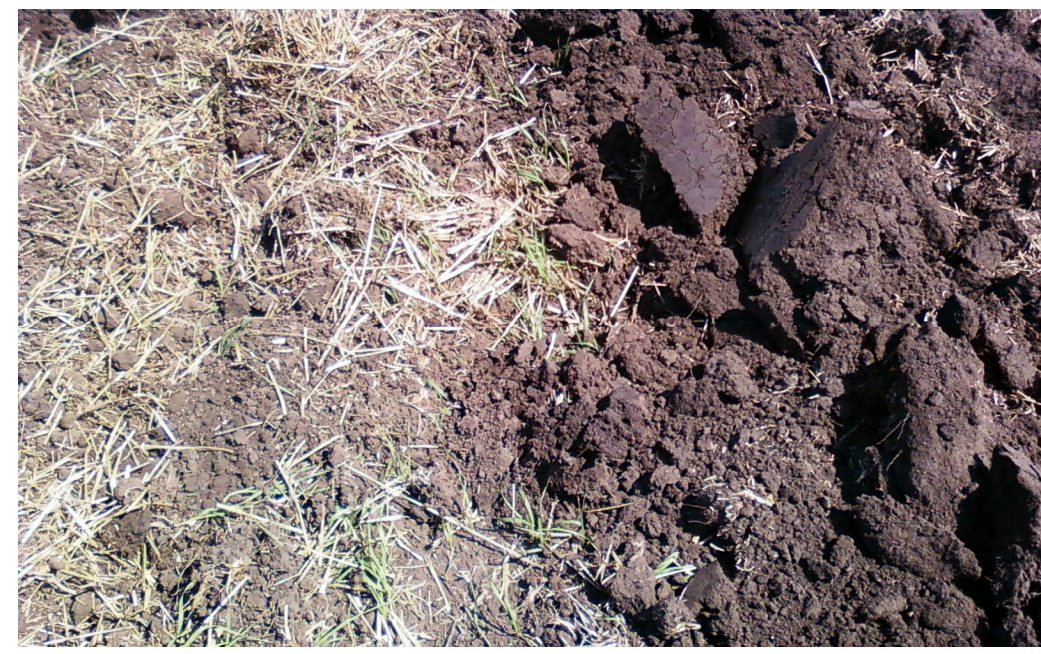

Fig. 2. Comparison of the background after the plow and new operating devices. 
Studies have shown that when processing the soil with moldboard plow, wet layers are carried out from the depths to the soil surface due to the turnover of the formation. The process of moistening the soil surface after processing with moldboard operating device (on the right in Figure 2) is visually determined, quantitative assessment is presented in Table 2 .

Table 2. The results of the study of the moisture content in the soil after the passage of new operating devices and the mouldboard plow at operating on different backgrounds.

\begin{tabular}{|c|c|c|c|}
\hline \multirow[b]{2}{*}{$\begin{array}{c}\text { The variant of the } \\
\text { new operating } \\
\text { device }\end{array}$} & \multirow[b]{2}{*}{ Background } & \multicolumn{2}{|c|}{ Indicator value } \\
\hline & & $\begin{array}{l}\text { Humidity in the layer } \\
\text { of } 0-5 \mathbf{~ c m} \text { after tillage } \\
\qquad W_{\text {after }}, \quad \%\end{array}$ & $\begin{array}{c}\text { Change in moisture } \\
\text { content in the layer of } \\
0-5 \mathrm{~cm} \\
\xi, \%\end{array}$ \\
\hline \multirow{3}{*}{$\begin{array}{l}\text { Operating devices } \\
\text { for layer-by-layer } \\
\text { tillage }\end{array}$} & background I & $22.5-25.0$ & reduced by $0-9.3$ \\
\hline & background II & $21.6-22.1$ & reduced by $1.3-3.6$ \\
\hline & background III & $17.9-18.3$ & reduced by $3.2-4.6$ \\
\hline Moldboard plow & background I & 30.9 & increased by 11.1 \\
\hline
\end{tabular}

From the analysis of the data in Table 2, it follows that when operating with moldboard operating device the moisture of the field surface after processing increases by $11.1 \%$ due to the observed movement of the layers. The topsoil is immediately subjected to desiccation due to evaporation of moisture with an unprotected mulch covering from plant and crop residues of the field surface. Accordingly, drier soil from the surface with moldboard plow moves deeper into the formation with a general loss of moisture in the treated layer. Comparing with new operating devices, the total decrease in moisture content using moldboard plow reaches up to $19.4 \%$, without taking into account losses inside the formation. Agrotechnical requirements differ for subsurface and moldboard tillage, therefore, the possibility of further use of sowing machines without additional processing was considered as a criterion, while the insignificant moisture reserves inside the formation in arid conditions should be preserved. Removal of wet layers to the field surface after soil cultivation with a moldboard plow and subsequent loosening to destroy blocks and soil surface leveling before sowing lead to desiccation of the formation and worsening conditions for the emergence of thick seedlings, growth and development of crops, which ultimately negatively affects productivity.

Basing on the results of the studies, using the developed modeling techniques [10-14], the layer-by-layer summation method based on the divergence theorem to calculate the internal dissipation rate [15], it is planned to determine the optimal parameters of the operating devices and establish rational modes of functioning of the technical equipment taking into account physical and mechanical properties of the processed medium (moisture and soil hardness).

\section{Conclusion}

Methodology has been developed to study the moisture content in the soil immediately after exposure to operating devices, basing on method for comparing the moisture content of different soil layers in the vertical direction.

The obtained results of the study indicate that the new operating devices ensure the conservation of subsoil moisture, do not carry out wet layers to the field surface, in contrast to the moldboard plow, the total decrease in moisture content reaches up to $19.4 \%$, without taking into account losses inside the formation. 


\section{References}

1. G.J. Burton, D.S. Shend, C. Cambell, Géotechnique Letters 4(2), 88-93 (2014) http://doi.org/10.1680/geolett.14.00003

2. J.M. Konrad, M. Lebeau, Canadian Geotechnical Journal 52(12), 2067-2076 (2015) https://doi.org/10.1139/cgj-2014-0300

3. V.R. Akuraju, D. Ryu, B. George, Y. Ryu, K. Dassanayake, Agric. For. Meteorol. 232, 489-499 (2017) https://doi.org/10.1016/j.agrformet.2016.10.007

4. Y. Fang, Y.Du, J. Wang, A. Wu, S. Qiao, B. Xu, S. Zhang, K.H.M. Siddique, Y. Chen, Front. Plant Sci. (2017) https://doi.org/10.3389/fpls.2017.00672

5. B. Ehdaie, A. P. Layne, J. G. Waines, Root system plasticity to drought influences grain yield in bread wheat 186, 219-232 (2012) https://doi.10.1007/s10681-011-0585-9

6. D. Helmana, I.M. Lenskya, D.J. Bonfilb, Early prediction of wheat grain yield production from root-zone soil water content at heading using Crop RS-Met 232, 1123 (2019) https://doi.org/10.1016/j.fcr.2018.12.003

7. O. Miller, D. Helman, T. Svoray, E. Morin, D. J. Bonfil, Field Crops Research 231 (2018) https://doi.10.1016/j.fcr.2018.11.011

8. V. Telichenko, A. Ter-Martirosyan, V. Sidorov, Procedia Engineering 165, 1359-1366 (2016) https://doi:10.1016/j.proeng.2016.11.865

9. A. Qin, D. Sun, J., Computers and Geotechnics 62, 110-117 (2014) https://doi.org/10.1016/j.compgeo.2014.06.014

10. S.G. Parkhomenko, G.G. Parkhomenko, Tractors and Agricultural Machinery 4, 55-62 (2018)

11. S.G. Parkhomenko, G.G. Parkhomenko, Innovatsii v Sel'skom Khozyaystve 4(29), 216-223 (2018)

12. G.G. Parkhomenko, S.G. Parkhomenko, Machinery Technical Service 2(135), 40-46 (2019)

13. S.G. Parkhomenko, Modeling of the wheeled tractor operation with a cultivator (Interagromash, Rostov-on-Don, 2019) https://doi.10.23947/interagro.2019.6.262-266

14. S.G. Parkhomenko, Modeling of the grain crushers downloading process (Interagromash, Rostov-on-Don, 2019) https://doi.10.23947/interagro.2019.6.267-271

15. L. Wang, W. Hu, D.A .Sun, L. Li, International Journal for Numerical and Analytical Methods in Geomechanics (2019) https://doi.10.1002/nag.2889

16. S.I. Kambulov, I.V. Bozhko, A.V. Olshevskaya, MATEC Web of Conferences 224, 05022 (2018) https://doi.org/10.1051/matecconf/201822405022

17. Yu.A. Ivanov, V.I. Pakhomov, S.I. Kambulov, D.V. Rudoi, ICMTMTE 2018 MATEC Web of Conferences 224, 05023 https://doi.org/10.1051/matecconf/201822405023

18. Y. Lachuga, A. Soloviev, A. Matrosov, I. Panfilov, V. Pakhomov, D. Rudoy, IOP Conf. Series: Earth and Environmental Science 403, 012055 (2019) doi:10.1088/1755$1315 / 403 / 1 / 012055$

19. G. Parkhomenko, S. Kambulov, A. Olshevskaya, A. Babadzhanyan, N. Gucheva, I. Mekhantseva, IOP Conf. Series: Earth and Environmental Science 403, 012144 (2019) doi:10.1088/1755-1315/403/1/012144 
20. E. Zubrilina, I. Markvo, V. Novikov, A. Beskopylny, L. Vysochkina, D. Rudoy, A. Butovchenko, IOP Conf. Series: Earth and Environmental Science 403, 012063 (2019) doi:10.1088/1755-1315/403/1/012063

21. V. Zhurba, Y. Chayka, N. Gucheva, D. Ushakov, N. Ugrekhelidze, N. Kulikova, M. Egyan, E3S Web of Conferences 135, 01087 (2019) ITESE-2019 https://doi.org/10.1051/e3sconf/201913501087

22. V.V. Ivanov, S.I. Popov, E.M. Selemeneva, N.T. Babazhanov, DTS-2019: AIP Conference Proceedings 2188 (2019) doi.org/10.1063/1.5138389

23. V.V. Ivanov, S.I. Popov, Ju.V. Marchenko, E.V. Marchenko, N.S. Dontsov, S.A. Timofeev, INTERAGROMASH 2019: IOP Conference Series: Earth and Environmental Science 403 (2019) doi:10.1088/1755-1315/403/1/012115

24. V.V. Ivanov, S.I. Popov, A.V. Kirichek, Key Engineering Materials 736, 18-22 (2017) DOI:10.4028/ www.scientific.net/ KEM.736.18 